\title{
ACUTE LUNG FIBROSIS FOLLOWING PARAQUAT POISONING
}

\author{
APARNA DAS ${ }^{1}$, NAZIHA SABAH NEERA ${ }^{2}$, FORHAD UDDIN HASAN CHOWDHURY ${ }^{3}$, MD AZIZUL KAHHAR ${ }^{4}$
}

\begin{abstract}
Paraquat is a potentially toxic herbicide that is used to eradicate common weeds. It is classified as a moderately hazardous (grade 2) pesticide by World Health Organization (WHO). Poisoning by paraquat carries significant mortality. It has an inclination to accumulate in lungs accelerating pulmonary fibrosis. We present a case report of a young man who accidentally ingested a mouthful of paraquat and subsequently developed fibrosis of lungs.
\end{abstract}

Keywords: Paraquat, Herbicide, Lung fibrosis.

Received: 05 November 2017

Accepted: 28 November 2017

DOI: http://dx.doi.org/10.3329/bjmed.v29i1.35407

\section{Introduction}

Paraquat (1,12 -dimethyl-4,42 -bipyridinium dichloride) is a commonly used herbicide in agriculture. Poisoning by Paraquat has become a common phenomenon in our country. Yet, the physicians are facing difficulty while treating the cases because of lack of an antidote or specific management guideline. This potentially toxic agent accumulates in high concentration in type $1 \& 2$ alveolar cells in lungs and proximal convoluted tubules in kidney after rapid absorption. It may cause acute necrosis of gastrointestinal tract, liver, adrenal cortex and hemorrhage, edema in the brain ${ }^{1}$. The main target organ is the lung, where its concentration remains 6 to 10 times higher even after blood and urine levels have fallen ${ }^{2}$. After accumulating in the cells it results in redox cycling and generates reactive oxygen species (ROS). These ROS causes lung injury resulting in rapid proliferation of fibroblasts leading to progressive fibrosis Paraquat is excreted unchanged in the urine. A study showed the patients fully developed acute kidney injury (AKI) at the fifth day after poisoning and normalized within 3 weeks without exception ${ }^{3}$. This case reports portrays a patient with sub lethal dose of Paraquat poisoning who developed acute kidney injury and progressive lung fibrosis.

\section{Case Summary}

An 18-year old young male farmer cum shopkeeper was brought to the emergency department with shortness of breath and oliguria seven days after accidental ingestion of a mouthful of commercially available paraquat (20\%) formulation. Initially, he was admitted in a local hospital having only vomiting. He was given supportive treatment but gastric lavage or oral adsorbents were not given. As he felt better he was discharged with advice.

But seven days later, he developed shortness of breath for which he was referred to Dhaka Medical College Hospital. The breathlessness was associated with dry cough, dysphonia and burning sensation in the mouth. He developed oliguria, passing about $250 \mathrm{ml}$ urine each day. He denied any history of hemoptysis, chest pain, difficulty in swallowing, abdominal pain or alteration of bowel habit.

On examination, his GCS was 15/15, dyspnoeic, cyanosed. His pulse rate was $96 \mathrm{bpm}$, regular, BP $110 / 70 \mathrm{~mm} \mathrm{Hg}$, temperature was $99^{\circ} \mathrm{F}$, Respiratory rate was 32 breaths per minute. His tongue showed erythematous patchy erosions characteristic of paraquat -tongue. Examination of cardiovascular and respiratory system revealed no abnormality except bilateral basal crepitations. Oxygen saturation was $66 \%$.

\section{Authors' information}

1. Associate Professor, Department of Medicine, Dhaka Medical College.

2. HMO, Department of Medicine, Dhaka Medical College.

3. A/ R Department of Medicine, Dhaka Medical College

4. Professor, Department of Medicine, Dhaka Medical College.

Address of Correspondence: Dr. Aparna Das, Associate Professor, Department of Medicine, Dhaka Medical College. Email: aparna_0191@yahoo.com

Bangladesh J Medicine 2018; 29 : 41-44 
Investigation shows:

\begin{tabular}{|c|c|}
\hline Complete blood count & $\begin{array}{l}\text { TC o f WBC } 14,300 / \mathrm{cu} \mathrm{mm} \\
\text { - Neutrophil } 75.3 \% \\
\text { - Lymphocyte } 13.4 \% \\
\mathrm{Hb} 14.7 \mathrm{~g} / \mathrm{dl} \\
\text { RBC } 5.20 \mathrm{~m} / \\
\text { Platelet } 2,73,000 / \mathrm{cu} \mathrm{mm}\end{array}$ \\
\hline ESR & $25 \mathrm{~mm}$ in $1^{\text {st }}$ hour \\
\hline Serum Creatinine & $4.73 \mathrm{mg} / \mathrm{dl}$ (raised $>3$ times) \\
\hline Serum electrolyte & Sodium $139 \mathrm{mmol} /$ LPotassium $2.9 \mathrm{mmol} / \mathrm{L}$ \\
\hline Serum Bilirubin & $2.80 \mathrm{mg} / \mathrm{dl}$ \\
\hline SGPT & 127U/L (raised 2.5 times) \\
\hline ECG & Sinus Tachycardia \\
\hline Echocardiography & Normal (LVEF 64\%) \\
\hline Arterial blood gas analysis & $\begin{array}{l}\text { - } \mathrm{pH} 7.483 \\
\text { - } \mathrm{pCO}_{2} 32.5 \text { torr } \\
\text { - } \mathrm{pO}_{2} 125.7 \text { torr } \\
\text { - Bicarbonate } 24.3 \mathrm{mmol} / \mathrm{L} \text { (respiratory alkalosis) }\end{array}$ \\
\hline HRCT scan of chest & Bilateral lung fibrosis \& pleural thickening \\
\hline Spirometry & $\begin{array}{l}\text { - } \mathrm{FEV}_{1} / \mathrm{FVC} 91.8 \% \text { (predicted } 84 \% \text { ) } \\
\text { - Post bronchodilator } \mathrm{FEV}_{1} \text { showed no improvement. } \\
\text { - } \mathrm{TLC} 1.84 \mathrm{~L} \text { (predicted } 5.14 \mathrm{~L} \text { ) } \\
\text { - Corrected } \mathrm{DL}_{\mathrm{CO}} 7.68 \mathrm{ml} / \mathrm{min} / \mathrm{mm} \mathrm{Hg} \text { (predicted } 29.23 \mathrm{ml} / \mathrm{min} / \mathrm{mm} \mathrm{Hg} \text { ) }\end{array}$ \\
\hline
\end{tabular}

The patient was treated with low flow humidified oxygen (later discontinued), nebulization with salbutamol and ipratropium bromide, injection methylprednisolone and injectable antibiotic. Adequate hydration was maintained.

After getting five days of methylprednisolone therapy, the patient's subjective well being improved considerably. But, he still had tachypnoea (36 breaths/min) and tachycardia $(114 \mathrm{~b} / \mathrm{min})$. Oxygen saturation increased to $88 \%$. Serum creatinine became normal with adequate urine output. The patient was discharged at 4 weeks of hospital admission with high dose oral steroid and antioxidant therapy.

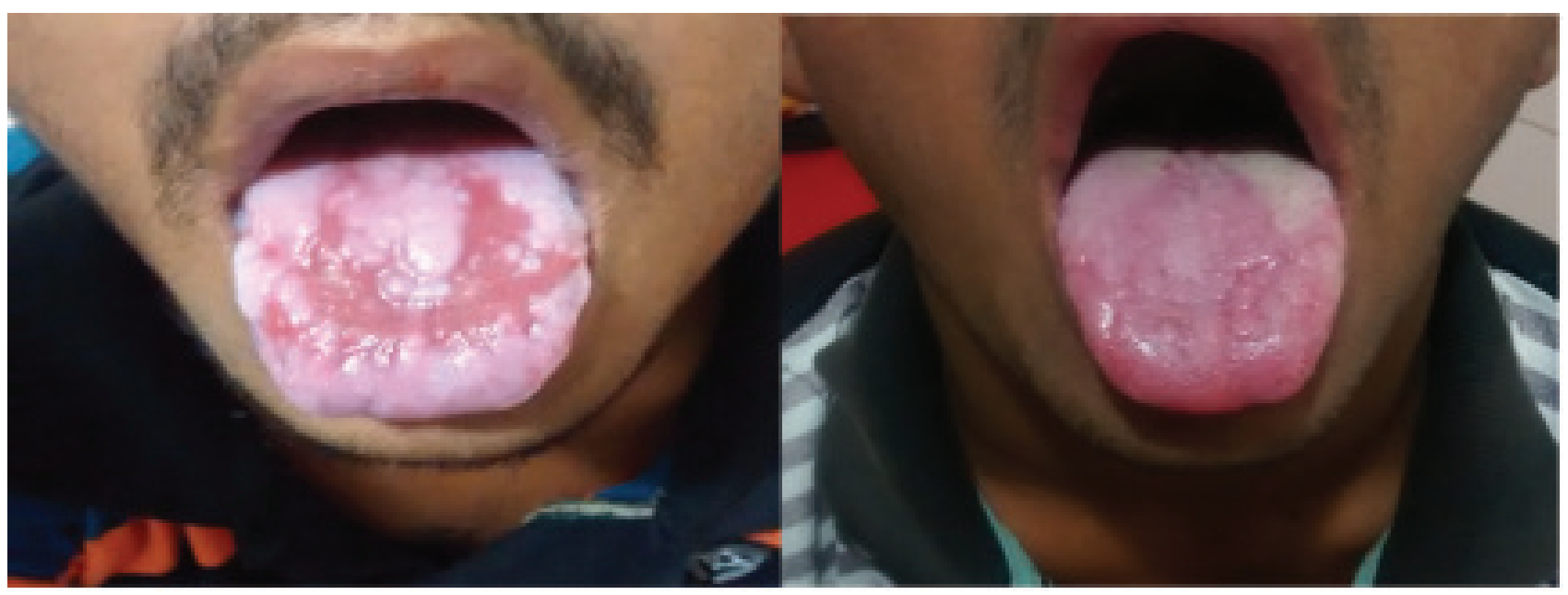

Fig.-1: Paraquat-tongue: just after poisoning

Fig.-2: Paraquat-tongue: one month later 


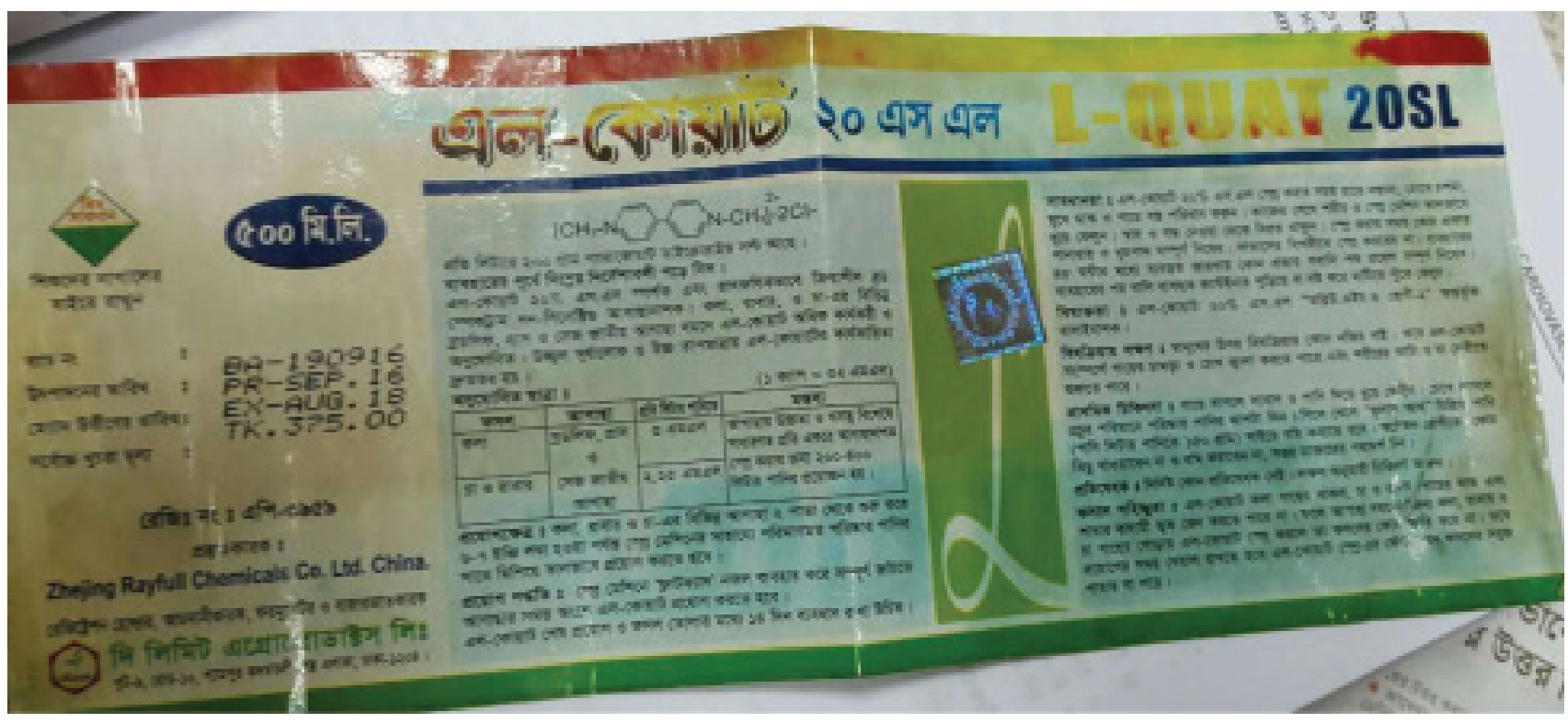

Fig.-3: The covering of the bottle of poison showing its ingredients

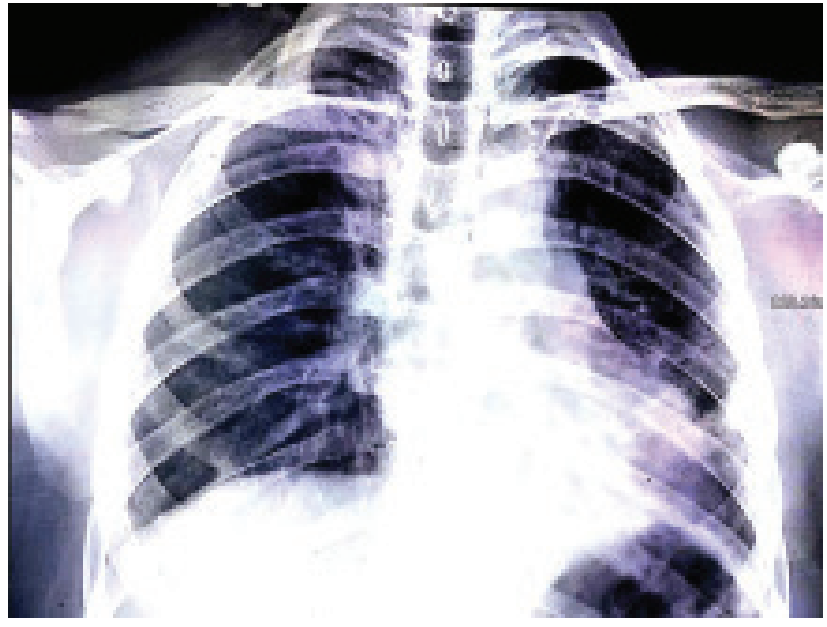

Fig.-4: Chest X-ray $P / A$ view, taken several days after poisoning.

\section{Discussion}

The commonest presentation of paraquat poisoning is kidney and lung involvement as evidenced by this case. In one study, $>50 \%$ of 278 patients developed AKI with approximately $35 \%$ having RIFLE (risk, injury, failure, loss, end-stage: KDIGO criteria of AKI) class 'failure' (3). The acute kidney injury in this patient can also be classified as 'failure' as serum creatinine was raised more than 3 times from the baseline. Mild hepatic dysfunction was observed in this patient initially which improved within a few weeks. The gastrointestinal symptoms occur due to caustic irritation effect which was not prominent in this patient. At intermediate dose, pulmonary edema

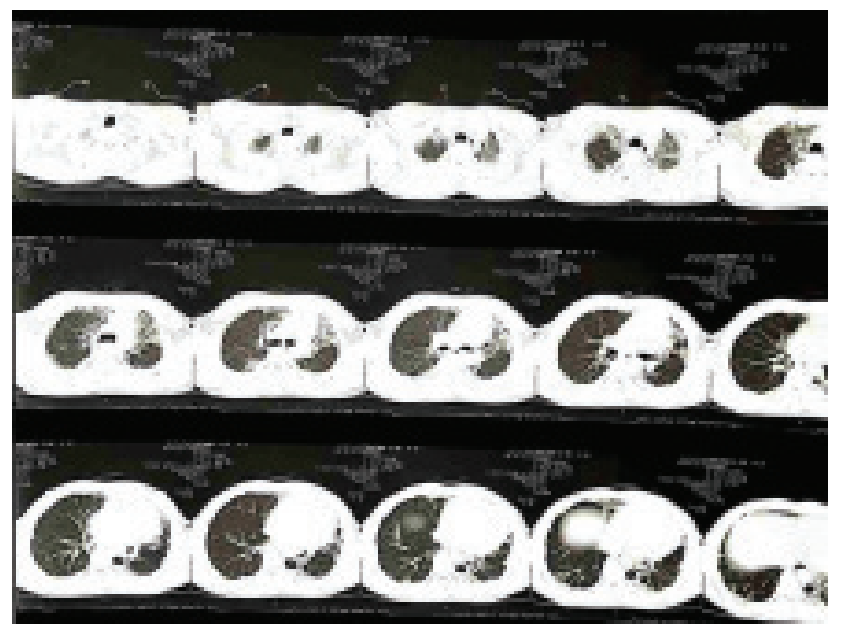

Fig.-5: HRCT scan of chest

develops within 24-48 hours; lack of surfactant causes hypoxemia and may resemble acute respiratory distress syndrome ${ }^{4}$. At large dose $(30 \mathrm{mg} / \mathrm{kg}$ body weight), multiorgan failure may occur upto 6 weeks after poisoning. Disease progression in lungs is marked by rapidly worsening respiratory distress, hypoxemia and restrictive lung defect with decreased lung compliance and diffusion capacity ${ }^{4}$. As expected, the spirometry showed severe restrictive abnormality with reduced $\mathrm{DL}_{\mathrm{CO}}$.

Although high dose immunosuppressive therapy with injectable cyclophosphamide $(5 \mathrm{mg} / \mathrm{kg} /$ day) and dexamethasone $(24 \mathrm{mg} /$ day) for 14 days have been correlated with $75 \%$ survival rate ${ }^{5}$, a subsequent study 
did not demonstrate its usefulness. Pulse therapy with methylprednisolone and cyclophosphamide may be effective in preventing respiratory failure and reducing mortality in patients with moderate to severe paraquat poisoning ${ }^{6}$. However, pulse therapy with methylprednisolone only is known as a strong antiinflammatory treatment suppressing ROS production by neutrophils and macrophages ${ }^{6}$. We treated our patient only methylprednisolone because amount of intake of paraquat was very small and got much improvement of his symptoms after treatment. Supplemental oxygen therapy may worsen the outcome of patient ${ }^{(2)}$. Gastric lavage should be avoided as paraquat is caustic. Increased GI adsorption and elimination by Bentonite, Fuller's Earth or activated charcoal can be given ${ }^{7}$. Desferrioxamine inhibits iron chelation, ultimately reducing paraquat induced free radical generation. It also blocks uptake of paraquat by type 2 alveolar cells ${ }^{8}$. Pirfenidone is able to reduce pulmonary fibrosis in a rat model but the increase in survival was insignificant ${ }^{9}$. There was little effect of Endothelin-I receptor blocker (Bosentan) to prevent fibrosis ${ }^{10}$. Extracorporeal elimination like hemodialysis, hemofiltration or hemoperfusion did not have effect on survival unless used just after (within 2 hours) poisoning ${ }^{7}$, therefore hemodialysis was not performed in this patient. Vitamin E supplement has failed to show any survival benefit, but both vitamin $\mathrm{E}$ and vitamin $\mathrm{C}$ prevent cytotoxicity by scavenging free radicals. $\mathrm{N}$-acetylcysteine may have a role in scavenging ROS, reducing inflammation. ${ }^{11}$. Early lung transplantation has been unsuccessful because of the cellular accumulation of paraquat resulting in fibrosis of the transplanted lung ${ }^{12}$.

The main cause of delayed mortality is progressive lung fibrosis whereas early mortality occurs as a result of circulatory collapse. There are many tools to assess the prognosis of paraquat poisoning. Plasma paraquat concentration has the greatest prognostic value but it is not commonly available. A simple yet effective way to predict 30-day mortality is measurement of neutrophil-lymphocyte ratio (NLR). Acute paraquat poisoning causes leukocytosis, neutrophilia and lymphopenia reflecting oxidative stress due to free radical induced chemokine production. An increase in NLRe" 10.57 showed 85\% mortality rate ${ }^{(13)}$. The calculated NLR for this patient on admission was 5.62 , predicting a 30 -day mortality rate to be only $14.7 \%$.

\section{Conclusion}

The likelihood of poisoning with a herbicidal agent like paraquat in our country is presumed to be high. The high mortality rate and lack of an antidote and an appropriate treatment protocol have created a challenging situation for physicians to deal with such cases. Even after survival, the rapid development of notorious complications as observed in this case call for our attention on the management of this potentially toxic substance.

\section{Consent}

Written informed consent was obtained from the patient for the publication of this case report.

\section{References}

1. Smith L, Rose M, Wyatt I. The Pathology and Biochemistry of Paraquat. Novartis Foundation Symposia. 2008;38:321-341. DOI: 10.1002/ $9780470715413 . \operatorname{ch} 18$

2. Dinis-Oliveira R, Duarte J, Sánchez-Navarro A, Remião F, Bastos $M$, Carvalho F. Paraquat Poisonings: Mechanisms of Lung Toxicity, Clinical Features, and Treatment. Critical Reviews in Toxicology. 2008;38(1):13-71.

3. Murray J, Mason R. Murray and Nadel's textbook of respiratory medicine. 5 th ed. Philadelphia: Saunders Elsevier; 2010:1626.

4. Kim S, Gil H, Yang J, Lee E, Hong S. The clinical features of acute kidney injury in patients with acute paraquat intoxication. Nephrology Dialysis Transplantation. 2008;24(4):1226-1232.

5. Addo E, Poon-King T. Leucocyte supression in treatment of 72 patients with paraquat poisoning. The Lancet. 1986;327(8490):1117-1120.

6. Lin J, Wei M, Liu Y. Pulse therapy with cyclophosphamide and methylprednisolone in patients with moderate to severe paraquat poisoning: a preliminary report. Thorax. 1996;51(7):661-663.

7. Freda B, Braden G. Other toxic acute tubulointerstitial nephritis. In: Hornblower S, Turner N, ed. by. Oxford Textbook of Clinical Nephrology. 4th ed. Oxford University Press, 2015: 688.

8. Seifirad S, Keshavarz A, Taslimi S, Aran S, Abbasi $H$, Ghaffari A. Effect of pirfenidone on pulmonary fibrosis due to paraquat poisoning in rats. Clinical Toxicology. 2012;50(8):754-758.

9. Zhang Z, Jian X, Zhang W, Wang J, Zhou Q. Using Bosentan to Treat Paraquat Poisoning-Induced Acute Lung Injury in Rats. PLoS ONE. 2013;8(10):e75943.

10. Gawarammana I, Buckley N. Medical management of paraquat ingestion. British Journal of Clinical Pharmacology. 2011;72(5):745-757.

11. Chiang W, Wang R. Pesticide Poisoning. In: Irwin R, Rippe J, ed. by. Irwin and Rippe's Intensive Care Medicine. 6th ed. Philadelphia: Lippincott Williams \& Wilkins; 2008: 1671.

12 Zhou D, Zhang H, Luo Z, Zhu Q, Zhou C. Prognostic value of hematological parameters in patients with paraquat poisoning. Sci. Rep.6, 36235; doi: 10.1038/ srep36235 (2016) 